\title{
A population genetic assessment of coral recovery on highly disturbed reefs of the Keppel Island archipelago in the southern Great Barrier Reef
}

Madeleine J van Oppen, Vimoksalehi Lukoschek, Ray Berkelmans, Lesa M Peplow, Alison M Jones

[p] Coral reefs

surrounding the islands lying close to the coast are unique to the Great Barrier Reef (GBR) in that they are frequently exposed to disturbance events including floods caused by cyclonic rainfall, strong winds and occasional periods of prolonged above-average temperatures during summer. In one such group of islands in the southern GBR, the Keppel Island archipelago, climate-driven disturbances frequently result in major coral mortality. Whilst these island reefs have clearly survived such dramatic disturbances in the past, the consequences of extreme mortality events may include the loss of genetic diversity, and hence adaptive potential, and a reduction in fitness due to inbreeding, especially if new recruitment from external sources is limited. Here we examined the level of isolation of the Keppel Island group as well as patterns of gene flow within the Keppel Islands using 10 microsatellite markers in nine populations of the coral, [i] Acropora millepora [i] . Bayesian cluster analysis and assignment tests indicated gene flow is restricted, but not absent, between the outer and inner Keppel Island groups, and that extensive gene flow exists within each of these island groups. Comparison of the Keppel Island data with results from a previous GBR-wide study that included a single Keppel Island population, confirmed that $A$. millepora in the Keppel Islands is genetically distinct from populations elsewhere on the GBR, with exception of the nearby inshore High Peak Reef just north of the Keppel Islands. We compared patterns of genetic diversity in the Keppel Island populations with those from other GBR populations and found them to be slightly, but significantly lower, consistent with the archipelago being geographically isolated, but there was no evidence for recent bottlenecks or deviation from mutation-drift equilibrium. A high incidence of private alleles in the Keppel Islands, particularly in the outer islands, supports their relative isolation and contributes to the 
conservation value of the archipelago. The lack of evidence for genetic erosion, in combination with our observation that the North Keppel Island population samples collected in 2002 and 2008, respectively, exhibited a pairwise genetic distance of zero, supports previous published work indicating that, following bleaching, Acropora corals in the Keppel Islands predominantly recover from regrowth of small amounts of remaining live tissue in apparently dead coral colonies. This is likely supplemented by recruitment of larvae from genetically similar, less disturbed populations at nearby reefs, particularly following extreme flood events. [p] 
1 A population genetic assessment of coral recovery on highly disturbed reefs of the Keppel Island

2 archipelago in the southern Great Barrier Reef

4 Abstract

5 Coral reefs surrounding the islands lying close to the coast are unique to the Great Barrier Reef (GBR) in

6 that they are frequently exposed to disturbance events including floods caused by cyclonic rainfall, strong

7 winds and occasional periods of prolonged above-average temperatures during summer. In one such

8 group of islands in the southern GBR, the Keppel Island archipelago, climate-driven disturbances

9 frequently result in major coral mortality. Whilst these island reefs have clearly survived such dramatic

10 disturbances in the past, the consequences of extreme mortality events may include the loss of genetic

11 diversity, and hence adaptive potential, and a reduction in fitness due to inbreeding, especially if new

12 recruitment from external sources is limited. Here we examined the level of isolation of the Keppel Island

13 group as well as patterns of gene flow within the Keppel Islands using 10 microsatellite markers in nine

14 populations of the coral, Acropora millepora. Bayesian cluster analysis and assignment tests indicated

15 gene flow is restricted, but not absent, between the outer and inner Keppel Island groups, and that

16 extensive gene flow exists within each of these island groups. Comparison of the Keppel Island data with

17 results from a previous GBR-wide study that included a single Keppel Island population, confirmed that

18 A. millepora in the Keppel Islands is genetically distinct from populations elsewhere on the GBR, with

19 exception of the nearby inshore High Peak Reef just north of the Keppel Islands. We compared patterns

20 of genetic diversity in the Keppel Island populations with those from other GBR populations and found

21 them to be slightly, but significantly lower, consistent with the archipelago being geographically isolated,

22 but there was no evidence for recent bottlenecks or deviation from mutation-drift equilibrium. A high

23 incidence of private alleles in the Keppel Islands, particularly in the outer islands, supports their relative

24 isolation and contributes to the conservation value of the archipelago. The lack of evidence for genetic

25 erosion, in combination with our observation that the North Keppel Island population samples collected in

262002 and 2008, respectively, exhibited a pairwise genetic distance of zero, supports previous published 
27 work indicating that, following bleaching, Acropora corals in the Keppel Islands predominantly recover

28 from regrowth of small amounts of remaining live tissue in apparently dead coral colonies. This is likely

29 supplemented by recruitment of larvae from genetically similar, less disturbed populations at nearby

30 reefs, particularly following extreme flood events.

31

32 Madeleine J. H. van Oppen ${ }^{1,2}$, Vimoksalehi Lukoschek ${ }^{3}$, Ray Berkelmans ${ }^{1}$, Lesa M. Peplow ${ }^{1}$, Alison M.

33 Jones $^{4}$

$34{ }^{1}$ Australian Institute of Marine Science, PMB 3, Townsville Mail Centre, Queensland, 4810, Australia

$35{ }^{2}$ School of BioSciences, The University of Melbourne, Parkville, Melbourne, 3010, Victoria, Australia

$36{ }^{3}$ ARC Centre of Excellence for Coral Reef Studies, James Cook University, Townsville, Queensland

37 4811, Australia

$38{ }^{4}$ Central Queensland University, Rockhampton, Queensland, 4702, Australia

40 Corresponding author

41 Madeleine J. H. van Oppen

42 Australian Institute of Marine Science, PMB 3, Townsville Mail Centre, Queensland, 4810, Australia

43 School of BioSciences, The University of Melbourne, Parkville, Melbourne, 3010, Victoria, Australia

44 Phone: +61-0409267577

45 E-mail: $\underline{\text { m.vanoppen@aims.gov.au }}$

46

47

48 
Introduction

50 Coral reefs along the East Australian coastline are shaped by a range of factors and forces that include

51 coastal geomorphology, freshwater inundation and sediment runoff, hydrodynamics, unusually warm

52 summer sea surface temperatures caused by climate warming, as well as local weather patterns. These

53 forces cause recurring perturbations and in some regions result in frequent, high levels of coral mortality.

54 One of the largest inshore reef systems of the southern Great Barrier Reef (GBR) is comprised of the

55 fringing reefs surrounding the 15 islands of Keppel Bay, located $\sim 12 \mathrm{~km}$ from the mainland coast. The

56 Keppel Islands are renowned for their high disturbance regime, causing repeated widespread coral

57 mortality. A major flooding event occurred here in 1991 (Byron \& O'Neill 1992; Furnas 2003; Jones \&

58 Berkelmans 2014), which caused bleaching and a mortality of almost $85 \%$ of all corals and total mortality

59 of Acropora spp. down to $1.3 \mathrm{~m}$ below lowest tide level (Van Woesik et al. 1995). Thermal mass coral

60 bleaching affected $>60 \%$ of the corals in this area in 1998, 2002 and 2006 and caused significant coral

61 cover loss (e.g., $40 \%$ loss in 2006; Jones et al. 2011), particularly in shallow (0-6 m) reef areas

62 (Berkelmans et al. 2004; Jones et al. 2008; Diaz-Pulido et al. 2009).

63

64 Typically, larval recruitment on tropical reefs occurs either from local, sexually mature and healthy corals

65 or from nearby and occasionally distant source populations. Spatial and temporal patterns of recruitment

66 are often variable and can be driven by factors such as local wind patterns, prevailing winds, the direction

67 and strength of wind-driven currents, the proximity of other reefs, water depth, and structural complexity

68 (Hughes et al. 2000; Whitaker 2004; Underwood et al. 2007; van Oppen et al. 2008; Almany et al. 2009).

69 Preliminary genetic analyses indicate the Keppel Islands are likely an isolated system (van Oppen et al.

70 2011). Because larval input from external sources is generally considered crucial for recovery on reefs

71 that have suffered extensive coral mortality (Lukoschek et al. 2013), it is important to validate that larval

72 dispersal into the Keppel Island archipelago is restricted. However, the importance of external larval

73 sources may be overestimated if partial, rather than whole colony, mortality is common and rapid 
74 regrowth of surviving tissues ensues (Riegl \& Piller 2001; Gilmour et al. 2013), a process that is a key mechanism of recovery from bleaching for Acropora spp. in the Keppel Islands (Diaz-Pulido et al. 2009).

Here we examine the mechanisms underlying recovery in the common reef-building coral, Acropora millepora (Cnidaria; Scleractinia; Acroporidae), in the Keppel Islands using a population genetics approach. Specifically, we explore genetic structure, connectivity and diversity on nine shallow reefs throughout the Keppel Island region using high-resolution DNA microsatellite markers. We also compare

81 population genetic diversity and local population genetic structure of A. millepora in the Keppel Islands to 82 that of 19 reefs spanning much of the latitudinal range of the GBR and including one of the nine Keppel 83 Island reefs sampled six years earlier (van Oppen et al. 2011). We discuss the implications of our findings 84 in terms of the future management of the Keppel Island reefs.

\section{Material and methods}

87 The Keppel Bay Island archipelago lies $\sim 30 \mathrm{~km}$ north of the mouth of the Fitzroy River near

88 Rockhampton (Fig. 1). Like much of the inshore GBR, the reefs principally fringe the bay heads of the 89 islands and, to a lesser extent, the rocky coastal headlands (Hopley 2006). Wherever substantial reefs 90 exist, these are dominated by large stands of fast-growing 'structural' species such as the acroporids, 91 pocilloporids and poritids (Jones et al. 2011). One such coral, A. millepora (Scleractinia: Acroporidae), 92 grows prolifically between $0-6.0 \mathrm{~m}$ (lowest astronomical tide) forming shallow, expansive reef flats on 93 the leeward shores of islands in the Bay (Fig. 2). A. millepora is a common and ecologically important 94 species on the GBR, particularly on the inshore reefs. Like most Acroporidae, A. millepora reproduces 95 sexually via a single annual broadcast spawning event, and to a lesser extent via asexual reproduction 96 through fragmentation (Smith \& Hughes 1999). 


\section{Genetic characterisation}

115 DNA was extracted from the preserved samples based on a slightly modified version of the method by

116 Wilson et al. (2002). PCR primers and protocols for the ten microsatellite loci are described in van Oppen

117 et al. (2011) and Wang et al. (2009). Twelve microsatellite markers were used in the PCR reactions and

118 run in four multiplex reactions (Suppl. Table S1), however, two loci were not used because of

119 inconsistent amplification success.

\section{Data analysis}

122 MegaBACE Genetic Profiler Software Suite version 2 (GE Healthcare) was used to determine the 123 fragment sizes (alleles) of all samples. All automatic scoring was checked manually, and samples that 
124 yielded ambiguous or no signal were re-amplified and re-run or removed from the analysis. The new data

125 acquired in this study were first analysed separately and subsequently combined with previously obtained

126 data on the same species and using the same loci, but from 20 GBR locations spanning $12^{\circ}$ of latitude

127 (van Oppen et al. 2011) and including one site in the Keppel Islands (Nth Keppel Island). Because the van

128 Oppen et al. (2011) data were scored with a different software package (CEQ8800 system software,

129 version 10 ), the possibility existed that alleles were scored differently and a shift in allele size had

130 occurred between the two methods. A subset of 3-5 samples from the van Oppen et al. (2011) data set

131 harbouring the most common alleles was therefore selected for each locus, and rescored using the

132 MegaBACE software. Based on this comparison, the allele sizes of all samples and loci were adjusted to

133 match the van Oppen et al. (2011) study. The combined data set of the two studies is available in

134 Supplemental Data S1.

135

136 The probabilities of identity by random sexual mating (Waits et al. 2001) were calculated using an

137 AMOVA (Analysis of Molecular Variance) approach (Excoffier et al. 1992) in GenAlEx v6.501 (Peakall

138 \& Smouse 2006). Individuals sharing the same multilocus genotype (MLG) were inferred to be clone

139 mates if probabilities of identity by random sexual mating were small. If asexual reproduction was

140 inferred, all but one individual with this MLG were removed prior to further data analysis.

141

142 Genotypic Linkage Disequilibrium (LD) was assessed in GENEPOP (web version 4.0.10) by estimation

143 of exact p-values using the Markov chain method (Raymond \& Rousset 1995 ) using default settings. A

144 previous study for A. millepora using the same loci that included one site (Nth Keppel) from the Keppel

145 Islands, showed that despite the presence of null alleles, heterozygote deficits were mostly due to

146 biological rather than methodological factors (van Oppen et al. 2011). Despite the occurrence of some

147 instances of deviations from HWE (Suppl. Table S2), all analyses were therefore conducted on data

148 uncorrected for null alleles.

149 
Genetic diversity, population structure, gene flow and isolation by distance

151 Various aspects of genetic diversity and uniqueness were estimated in GenAlEx v6.501 including the

152 number of alleles per locus (Na), allelic richness (Ar), allelic evenness (Ae), observed $\left(H_{O}\right)$ and expected

$153\left(H_{E}\right)$ heterozygosities and private alleles. Differences in rarefacted allelic richness (using 22 individuals

154 per site, the smallest sample size in the data set) between the nine Keppel Island sites and the 19 other

155 sites from throughout the GBR were assessed in FSTAT 2.9.3 using a Mann-Whitney U test (Goudet

156 1995).

157

158 Populations that have experienced a recent reduction in their effective population size exhibit a reduction

159 in the allele numbers and transient heterozygous $\left(H_{O}\right)$ excess at polymorphic loci compared to that under

160 HWE $\left(H_{E}\right)$ (Cornuet \& Luikart 1996). If HWE is assumed (i.e., no recent bottleneck), there is an equal

161 probability of having a positive or a negative difference between the observed and the expected

162 heterozygosities. In contrast, following a recent bottleneck, heterozygous excess is expected to occur

163 more often than heterozygous deficit. Therefore, if the number of loci for which there is heterozygous

164 excess is significantly larger than that for which there is a heterozygous deficit, a recent bottleneck can be

165 inferred (Luikart \& Cornuet 1998). The heterozygosity distribution under the assumption of HWE and the

166 infinite allele mutation model was calculated for each of the nine Keppel Island sites and for each locus in

167 the software package Bottleneck 1.2.02. Bottlenecks are also expected to change the allele frequency

168 distribution (Cornuet \& Luikart 1996). Therefore, the allele frequency distribution was established to see

169 whether it was approximately L-shaped (as expected under HWE) or not.

170

171 Population structure within the Keppel Islands and the combined data sets was estimated using $F_{\mathrm{ST}}$ values

172 calculated using an AMOVA approach (Excoffier et al. 1992) in GenAlEx v6.501 (Peakall \& Smouse

173 2006) with significance tested using 999 permutations. Genetic differentiation between sites was

174 estimated in the following ways: (1) $F_{\mathrm{ST}}$ values were calculated using an AMOVA approach in GenAlEx

175 v6.501. To assess the significance of differentiation between sites, we applied a Fisher exact test (Goudet 
176 1995) using Genepop v4.0 with the default Markov chain parameters. Statistical significance for all

177 pairwise tests was adjusted for multiple comparisons by the B-Y False Discovery Rate (FDR) method

178 (Narum 2006). (2) Jost's (Jost 2008) actual measure of differentiation $\left(D_{\text {est }}\right)$ was computed in SMOGD

179 version1.2.5 (Crawford 2010). To visualise the genetic relationships among populations, the genetic

180 distance measures between pairs of Keppel Island sites were plotted using a Principal Coordinates

181 Analysis (PCoA) with GenAlEx v6.501. To determine whether there was a pattern of isolation-by-

182 distance (IBD), pairwise $D_{\text {est }}$ values were regressed onto over-water distances between sites and

183 significance tested using Mantel permutation test in IBD Web Service (Jensen et al. 2005).

184

185 Two fully Bayesian model-based clustering methods implemented in the programs STRUCTURE ver.

186 2.3.3 (Pritchard et al. 2000) and TESS ver. 2.3 (Chen et al. 2007; François \& Durand 2010) were used to

187 further examine spatial genetic structure for the Keppel Islands $(\mathrm{n}=370)$ and Keppel Islands plus the

188 GBR $(\mathrm{n}=1292)$ datasets. STRUCTURE analyses were conducted using both the admixture and no-

189 admixture models, each with correlated allele frequencies, using the sampling sites as prior (LOCPRIOR),

190 which has been shown to better resolve genetic structure when there is low genetic divergence (Hubisz et

191 al. 2009). MCMC chains used a burn-in of 50,000 chains followed by 500,000 of MCMC replications.

192 Ten independent chains were run for each $\mathrm{K}$ from $\mathrm{K}$ of 1 to 9 for the KI data and $\mathrm{K}$ of 1 to 15 for the

193 combined data. In each case, the most likely value of $\mathrm{K}$ was evaluated using the method of Evanno et al.

194 (2005) as implemented in STRUCTURE HARVESTER (Earl 2009). STRUCTURE implements an

195 algorithm that puts a strong emphasis on the prior of the existence of clusters, which may make it prone to

196 errors when geographical sampling is discrete along clines (Chen et al. 2007). TESS aims to address this

197 issue by using a spatially continuous prior based on the geographical coordinates of each sampled

198 individual. TESS was run using the CAR admixture model, which assumes spatial autocorrelation of the

199 genomes of individuals in closer geographical proximity compared with those further apart. The strength

200 of this autocorrelation is represented by a spatial interaction parameter $(\psi)$, which was set to the default

201 value of 0.6 for analysis. TESS was run with a burn-in of 10,000 sweeps followed by 25,000 sweeps, with 
20220 independent runs conducted for each value of $\mathrm{K}$ from $\mathrm{K}$ of 2 to 9 for the KI data and $\mathrm{K}$ of 2 to 15 for 203 the combined KI plus GBR data (TESS does not implement analyses for $\mathrm{K}=1$ ). For each value of $\mathrm{K}$, the 204 ten runs with the lowest DIC scores were used to calculate the average DIC and evaluate the most likely 205 number of genetic clusters. The coefficient of ancestry was calculated for each individual across all runs

206 for the most likely value of K in CLUMPP version 1.1.2 (Jakobsson \& Rosenberg 2007) and results

207 visualized with the program DISTRUCT version 1.1 (Rosenberg 2004).

208

209 GeneClass2 (Piry et al. 2004) was used to examine first generation migrants (i.e., recent gene flow) within

210 the Keppel Island archipelago (only the Keppel Island data were used for this analysis). In the first step of

211 this analysis, migrants were identified using the criteria and computational algorithm of Rannala and

212 Mountain (1997) with 10,000 simulated genotypes and an alpha of 0.01. The test statistic $L_{h}$ was used as

213 not all potential source populations had been sampled (Paetkau et al. 2004). Migrants were excluded from

214 the data set, and this adjusted data set served as the reference data set to which migrants were assigned.

215 Migrants were assigned to populations if the assignment probabilities were greater than 0.1 .

216

217 Results

218 Genetic diversity

219 All loci were polymorphic in all populations sampled, with numbers of alleles ranging from 2 to 17

220 (Suppl. Table S2). Expected heterozygosities ranged from 0.232 to 0.885 (Suppl. Table S2). Three MLGs

221 in the Keppel Islands data set were repeated twice each; two of these MLGs occurred at Barren Island and

222 one at Man \& Wife Rocks. One sample from each pair was removed prior to further analyses. The

223 resulting data set consisted of 370 MLGs from nine locations. Five, three, three, six, one, one, and two

224 instances (out of 45 pairwise comparisons within each population) of LD were observed in Barren Island,

225 Outer Rocks, Man \& Wife Rocks, Halftide Rocks, Nth Keppel Island, Humpy Island, and Passage Rocks,

226 respectively (Suppl. Table S3). No cases of LD were observed in the Miall and Halfway Island

227 populations. 
229 In the combined data set, rarefacted allelic richness was slightly, but statistically significantly lower 230 between the Keppel Island populations and all other GBR populations included in this study (6.7 versus 2317.3 alleles respectively, $\mathrm{p}=0.006$ ). Plots of allelic evenness (Suppl. Figs. S1A and B) confirm that, with

232 the exception of Man \& Wife Rocks, genetic diversity is consistently lower in the Keppel Islands

233 compared to elsewhere on the GBR. The Bottleneck analyses indicated all loci in all populations fit the

234 mutation-drift equilibrium, and there were no deviations from an L-shaped allele frequency distribution,

235 suggesting no recent bottlenecks have occurred.

236

237 Private alleles were found in 54 out of 1292 colonies of $A$. millepora from the combined GBR-Keppel

238 Islands data set, 23 (43\%) of which occurred in the Keppel Islands. Given the relatively small sample size

239 from Keppel Island populations (320 out of 1292, i.e., $25 \%$ of the total sample size), private alleles are

240 overrepresented in this archipelago. Twenty-one of the 23 Keppel Island samples with private alleles were

241 from the outer island group.

242

243

Population structure, gene flow and isolation by distance

244 AMOVA showed that 5\% of the total variance in the Keppel Island data set was partitioned among 245 populations $\left(\right.$ Global $\left.F_{\mathrm{ST}}=0.055, \mathrm{p}<0.001\right)$. Pairwise $F_{\mathrm{ST}}$ values were significant for all comparisons (B-

246 Y FDR; $\alpha_{\text {CRIT }}=0.012$ ) except for Halfway Island-Miall Island, Halfway Island-Nth Keppel Island and

247 Miall Island-Nth Keppel Island (Suppl. Table S4). The Barren Island population was highly divergent, 248 with most $F_{\mathrm{ST}}$ values $>0.1$. Twenty-six of 36 pairwise $D_{\text {est }}$ values were statistically significant, and the $D_{e s t}$ 249 values also indicated that the Barren Island population was highly divergent, with most values $>0.2$

250 (Table 1). This pattern is clearly visualised in the PCoA of pairwise $D_{\text {est }}$ values (Suppl. Fig. S2). There 251 was no evidence of IBD $\left(r^{2}=0.07, p=0.150\right.$; Suppl. Fig. S3), which is consistent with the pattern of 252 some geographically disparate pairs of sites being genetically similar (e.g., Halfway Island vs. Nth Keppel 
Island; Humpy Island vs. Nth Keppel Island; Table 1), while other geographically proximate sites are 254 genetically divergent (e.g., Man \& Wife Rocks vs. Halftide Rocks; Table 1).

Forty-two of the 370 Keppel Island individuals included in this study were identified as first generation migrants based on the GeneClass2 analysis (Suppl. Table S5). In the outer Keppel Islands, five out of 29 (Barren), three out of 28 (Man \& Wife) and six out of 50 (Outer) were identified as recent migrants. Four of these could not be assigned (i.e., had assignment probabilities $<0.1$ to all sampled populations), seven had the greatest probabilities for assignment to other outer reefs, three had high assignment probabilities to both inner and outer Keppel Island populations, while none were assigned to inner island populations only. Of the 28 migrants identified in the inner islands, 19 were assigned. Eight of these were assigned to one or more of the outer island populations, six to both inner and outer populations, and five to other inner island populations. These results suggest recent gene flow has occurred both within and between island groups, and that gene flow occurs from east to west and vice versa, but likely more frequently from east (outer islands) to west (inner islands).

267

STRUCTURE using the admixture model indicated that two or three genetic clusters best explained the genetic patterns of the multilocus genotypes of the 370 colonies of $A$. millepora in the Keppel Islands, with highest $\Delta K$ for $K=2$ followed by $K=3$ (Suppl. Fig. S4). Similarly, TESS DIC scores declined sharply between $\mathrm{K}=2$ and $\mathrm{K}=3$ and then declined much more slowly while variances in DIC increased markedly, providing support for three genetic cluster (Suppl. Fig. S4). STRUCTURE using the noadmixture model did not provide a clear result. TESS and STRUCTURE using the admixture model for K $274=2$ returned almost identical genetic patterns, with Passage Rocks, Halftide Rocks, Halfway, Humpy, 275 Miall and Nth Keppel Islands forming a panmictic cluster, while Barren Island, Man \& Wife and Outer 276 Rocks had some individuals from the panmictic cluster and others from the second genetic cluster (Suppl. 277 Fig. S5). TESS for $\mathrm{K}=3$ returned a similar pattern to $\mathrm{K}=2$ except that Man \& Wife Rocks was distinct 278 from Barren Island and Outer Rocks, with colonies that did not belong to the panmictic cluster belonging 
279 to the third genetic cluster (Suppl. Fig. S5). By contrast, STRUCTURE for K $=3$ found admixture

280 between the panmictic and the third genetic cluster within all individuals at Passage Rocks and

281 approximately half the individuals at Humpy Island (Suppl. Fig. S5). This result, combined with the

282 higher $\Delta \mathrm{K}$ for $\mathrm{K}=2$ than $\mathrm{K}=3$ suggests that, unlike TESS, the algorithm implemented in STRUCTURE

283 was unable to resolve Man and Wife Rocks as a distinct genetic cluster.

284

285 For the combined GBR plus Keppel Island data set, STRUCTURE results showed that $\Delta \mathrm{K}$ was highest

286 for $\mathrm{K}=2$ followed by $\mathrm{K}=3$ and then peaked again at $\mathrm{K}=5$, while TESS DIC values declined steeply

287 between $K=2$ and $K=5$ and then declined more slowly (Suppl. Fig. S6). Although $\Delta \mathrm{K}$ for $\mathrm{K}=5(\Delta \mathrm{K}=$ 288 20) was smaller than for $\mathrm{K}=2(\Delta \mathrm{K}=230)$ and $\mathrm{K}=3(\Delta \mathrm{K}=35)$, all were much larger than for all other

289 values of $\mathrm{K}$ (typically $\Delta \mathrm{K}<1$ ).). Given that TESS clearly delineated three genetic clusters for the Keppel

290 Islands alone, we present $\mathrm{K}=5$ for the combined dataset. All sites in the Keppel Island archipelago were

291 genetically distinct from GBR populations in the far northern, northern and central GBR reefs, as well as

292 most southern GBR reefs except High Peak (Fig. 1), which may receive larvae from the Keppel Islands

293 via the predominantly north-east flowing sea surface currents in this part of the GBR (Luick et al. 2007).

294 In particular, Barren Island and some individuals from Man \& Wife and Outer Rocks belonged to a

295 genetic cluster not found elsewhere on the GBR. Temporal samples from Nth Keppel Island (July 2002,

296 van Oppen et al. 2011; and 2008, this study) were genetically similar (Fig. 1) and had $F_{\text {ST }}$ values not

297 significantly different from zero (results not shown).

298

\section{Discussion}

\section{Limited gene flow between inner and outer island clusters}

301 The Barren Island population is a genetic outlier with $D_{\text {est }}$ values ranging from 0.175 to 0.253 (Table 1),

302 and most of the individuals sampled belong to a genetic cluster distinct from any other cluster observed

303 on the GBR (Fig. 1). The reasons underlying the extreme genetic distinctiveness of this population are

304 unclear. Outer and Man \& Wife Rocks have smaller numbers of individuals of the same distinct genetic 
305 affinity. Despite this, all three outer island populations contain some individuals that are of the inner

306 islands genetic affinity. Further, they show a signature of admixture with some colonies being comprised

307 of the distinct as well as the more typical inner island genetic cluster, suggesting some level of gene flow

308 exists between outer and inner islands. This was confirmed by assignment tests, which in addition

309 suggested gene flow is higher from east to west than from west to east, consistent with the predominant

310 direction of sea surface currents (Luick et al. 2007). A genetic parentage study of two coral reef fish

311 species found that recent dispersal rates were higher among the inner Keppel Islands than between Barren

312 Island and the inner islands (Harrison et al. 2012), consistent with our observations for A. millepora.

313

314 Coral larval competency is unlikely a limiting factor for gene flow of $A$. millepora as larvae of this

315 species are competent to metamorphose and settle around 4-5 days after spawning (Babcock \& Heyward

316 1986), with maximum rates of metamorphosis occur at eight days after spawning (Heyward \& Negri

317 1999). Maximum longevity of Acropora coral larvae in the water column, however, is much longer ( $\sim 60$

318200 days) (Nishikawa et al. 2003; Graham et al. 2008). Larval dispersal is affected by surface water

319 circulation patterns. Numerical particle experiments indicate that during the northward-current season (the

320 austral summer in which coral mass spawning takes place), cross-shelf particle dispersal is limited (Luick

321 et al. 2007), likely contributing to the population structure observed here. Alternatively, realised dispersal

322 may be lower than the actual dispersal potential due to maladaptation of outer island genotypes to inner

323 island environmental conditions and vice versa (Prada \& Hellberg 2014). While the environmental

324 factors light, temperature and habitat profile, current strength and reef rugosity (3-D habitat complexity)

325 do not show an east-west pattern (Jones et al. 2011) that explains the genetic differences observed

326 between inner and outer Keppel Island populations, further research is required to address the possibility

327 that maladapted genotypes are unable to survive despite cross-shelf dispersal and recruitment.

328

329 Mechanisms of recovery 
A. millepora populations in the Keppel Island archipelago are genetically isolated from most other

331 populations on the GBR (Fig. 1) and are therefore largely self-sustaining. Along the GBR, south easterly

332 trade winds dominate throughout the year but are seasonally displaced by northerly monsoonal winds

333 during the austral summer (Pickard 1977). The nearest mid-shelf reefs to the Keppel Islands are those of

334 the Capricorn Bunker Group, $>65 \mathrm{~km}$ to the east. South easterly winds could theoretically drive

335 recruitment between the Capricorn Bunkers and the Keppel Island group, but A. millepora is relatively

336 rare in the former (MvO \& VL, pers. obs.) and these reefs therefore unlikely serve as a source of larvae

337 for the Keppel Island populations. A. millepora has a relatively high dispersal potential due to its

338 broadcast-spawning mode of reproduction and long larval competency period. We hypothesise that, in the

339 Keppel Islands, other coral species with similarly high dispersal potential to A. millepora, as well as

340 species that disperse over shorter spatial distances, will also consist of primarily self-sustaining

341 populations (although the Capricorn Bunkers may be a source for high dispersal coral species that occur

342 at higher abundance there). This suggests that the archipelago is vulnerable to perturbations that cause

343 widespread high coral mortality, as recovery through the arrival of recruits from reefs outside the Keppel

344 Islands will be slow.

347 The 2002 Nth Keppel Island sample (collected prior to the 2002 bleaching event) exhibited no evidence

348 of a genetic bottleneck, which was unexpected given the high mortality experienced during the 1998 mass

349 bleaching event (Berkelmans et al. 2004). The same population showed an $F_{\text {ST }}$ value not significantly

350 different from zero when compared with the 2008 sample from the same location. In addition to the 2002

351 bleaching event, a mass bleaching episode occurred in the Keppel Islands in 2006, causing $40 \%$ loss in

352 coral cover (Jones et al. 2011). Given that severe bleaching reduces reproductive output in the subsequent

353 spawning season (Michalek-Wagner \& Willis 2001; Jones \& Berkelmans 2011), and that it would take at

354 least 2-3 years for new recruits to reach reproductive maturity even for the fast-growing Keppel Island

355 Acropora spp. (Omori 2010), there was little scope for local colonies that survived the 2002 and 2006 
356 bleaching events to contribute to coral recovery through larval recruitment by 2008 . This, in combination

357 with the lack of evidence for recent genetic bottlenecks in all Keppel Island populations studied here

358 (which were collected in 2008 and 2009), supports the hypothesis that in spite of reports of widespread

359 mortality, whole colony mortality was actually low following the 2002 and 2006 bleaching events

360 (although visual surveys that did not examine cryptic remnant tissues indicated whole colony mortality

361 was high) and that tissue regrowth, rather than external recruitment, was the main mechanism of recovery

362 following the two bleaching events. This supports the work of Diaz-Pulido et al. (2009) showing that

363 coral recovery had occurred unexpectedly rapidly (within 12 months) after bleaching from surviving

364 tissues in apparently dead colonies. Coral recruitment during this period was low (Diaz-Pulido et al.

365 2009) and instead, recovery must have occurred through regrowth from cryptic remnant tissues, as

366 supported by our genetic data. The unusually high growth rates of Acropora spp. in the Keppel Islands

367 (Diaz-Pulido et al. 2009; Jones \& Berkelmans 2010) appear to be key to this atypically rapid coral cover

368 recovery following disturbance.

369

370 Preliminary observations show that the speed of recovery following flood events is slower than that

371 following bleaching, likely reflecting the more common occurrence of whole colony mortality in areas

372 affected by fresh water inundation, despite its more spatially restricted impact. For example, the 1991

373 flooding event (Byron \& O'Neill 1992; Furnas 2003; Jones \& Berkelmans 2014) caused total mortality of

374 Acropora spp. down to $1.3 \mathrm{~m}$ below lowest tide (Van Woesik et al. 1995). Average coral cover at the

375 southern/western side of Nth Keppel Island (site 4 in Byron \& O'Neill 1992) dropped from pre-flood

376 levels of $51-75 \%$ to $10 \%$ post-flood (Byron \& O'Neill 1992) and had not yet fully recovered by February

3771995 ( $40 \%$ RB, unpubl.). Similarly coral cover on the southern/western side of Halfway Island (site 20

378 in Byron \& O'Neill 1992) dropped from 76-100\% before the 1991 flood to 50\% post-flood but were fully

379 recovered by August 1996 ( 84\%, RB, unpubl.). However, reefs on the northern and eastern sides of

380 these islands generally showed little coral loss (Byron \& O'Neill 1992; Van Woesik et al. 1995). Our

381 interpretation of these observations, in light of the population genetic results presented here, is that while 
382 whole colony mortality is more prominent during floods than bleaching, flooding has a spatially more

383 variable impact within the Keppel Islands. The slower recovery of flood impacted southern and western

384 sides of the islands was likely mostly due to larval recruitment from northern and eastern sites.

386 Management implications

387 The lack of evidence for genetic erosion in this study demonstrates that, despite four high mortality events

388 including flooding in 1991, and bleaching in 1998, 2002 and 2006, the resilience of coral populations in

389 the Keppel Islands was high prior to late 2008 - early 2009 when the sampling for this study was

390 conducted. However, in this isolated reef system, recruitment from external sources is limited, potentially

391 placing future recovery at risk if disturbance events are too frequent or are severe enough to cause

392 widespread whole-colony mortality.

393

394 The isolation of the Keppel Island archipelago and genetic distinctiveness of its coral populations have

395 implications for reef restoration actions and management interventions that may be considered in the

396 future. For instance, the introduction of coral genotypes from elsewhere, with the intent to accelerate

397 recovery and boost resilience (Hoegh-Guldberg et al. 2008; van Oppen et al. 2014), may have positive

398 effects as a consequence of introducing new gene variants into the Keppel Island populations if

399 introduced colonies interbreed with the remaining native corals, but could also have adverse effects due to

400 outbreeding depression. This requires testing under controlled conditions before such measures would be

401 implemented. The Keppel Island corals possess a set of valuable traits, including genetic distinctiveness,

402 high growth rates and recovery potential, which, in combination with their relative isolation from other

403 reefs should afford these ecosystems a high conservation status.

404

405 Conclusions

406 Our microsatellite genotyping results demonstrate that populations of the common reef builder, $A$.

407 millepora, in the Keppel Islands fall into two clusters with limited gene flow; those at the inner islands 
408 versus those at the outer islands (i.e., Barren Island, Outer Rocks and Man \& Wife Rocks). Further,

409 populations of this species in the Keppel Island archipelago are self-sustaining and receive very little

410 input from populations elsewhere on the GBR. Genetic diversity analyses suggest coral recovery in the

411 Keppel Islands often occurs from surviving colony regrowth rather than by recruitment from external

412 sources, especially following bleaching. However, when whole colony mortality is widespread within a

413 reef but variable among reefs (as is the case with floods), recruitment from external, nearby reefs that

414 suffered low mortality can facilitate recovery.

415

416

\section{Acknowledgements}

418 The authors would like to thank Scott Gardner for assistance with sampling.

419 


\section{References}

421 Almany G, Connolly S, Heath D, Hogan J, Jones G, McCook L, Mills M, Pressey R, and Williamson D. 422 2009. Connectivity, biodiversity conservation and the design of marine reserve networks for coral 423 reefs. Coral Reefs 28:339-351.

424 Babcock RC, and Heyward A. 1986. Larval development of certain gamete-spawning scleractinian corals. $425 \quad$ Coral Reefs 5:111-116.

426 Berkelmans R, De'ath G, Kininmonth S, and Skirving WJ. 2004. A comparison of the 1998 and 2002 coral bleaching events on the Great Barrier Reef: spatial correlation, patterns, and predictions. Coral Reefs 23:74-83.

Byron GT, and O'Neill JP. 1992. Flood induced coral mortality on fringing reefs in Keppel Bay. Workshop on the Impact of Flooding. Townsville, Australia: Great Barrier Reef Marine Park Authority.

Chen C, Durand E, Forbes F, and François O. 2007. Bayesian clustering algorithms ascertaining spatial population structure: a new computer program and a comparison study. Molecular Ecology Notes 7:747-756.

Cornuet JM, and Luikart G. 1996. Description and power analysis of two tests for detecting recent population bottlenecks from allele frequency data. Genetics 144:2001-2014.

Crawford NG. 2010. smogd: software for the measurement of genetic diversity. Molecular Ecology Resources 10:556-557. DH, and Hoegh-Guldberg O. 2009. Doom and boom on a resilient reef: Climate change, algal overgrowth and coral recovery. PLoS ONE 4:e5239.

442 Earl DA. 2009. Structure Harvester v 0.56.3, http://taylor0.biology.ucla.edu/struct_harvest/.

443 Evanno G, Regnaut S, and Goudet J. 2005. Detecting the number of clusters of individuals using the 444 software STRUCTURE: a simulation study. Molecular ecology 14:2611-2620. 
445 Excoffier L, Smouse PE, and Quattro JM. 1992. Analysis of molecular variance inferred from metric 446 distances among DNA haplotypes: Application to human mitochondrial DNA restriction data. $447 \quad$ Genetics 131:479-491.

448 François O, and Durand E. 2010. Spatially explicit Bayesian clustering models in population genetics. 449 Molecular Ecology Resources 10:773-784.

450 Furnas M. 2003. Catchment and corals: Terrestrial runoff to the Great Barrier Reef. Townsville: 451 Australian Institute of Marine Science \& CRC Reef Research Centre.

452 Gilmour JP, Smith LD, Heyward AJ, Baird AH, and Pratchett MS. 2013. Recovery of an isolated coral 453 reef system following severe disturbance. Science 340:69-71.

454 Goudet J. 1995. Fstat version 1.2: a computer program to calculate Fstatistics. Journal of Heredity $455 \quad 86: 485-486$.

456 Graham EM, Baird AH, and Connolly SR. 2008. Survival dynamics of scleractinian coral larvae and 457 implications for dispersal. Coral Reefs 27:529-539.

458 Harrison HB, Williamson DH, Evans RD, Almany GR, Thorrold SR, Russ GR, Feldheim KA, van 459 Herwerden L, Planes S, Srinivasan M, Berumen ML, and Jones GP. 2012. Larval Export from 460 Marine Reserves and the Recruitment Benefit for Fish and Fisheries. Current Biology 22:1023-1028. 461 Heyward A, and Negri A. 1999. Natural inducers for coral larval metamorphosis. Coral Reefs 18:2732792.

463 Hoegh-Guldberg O, Hughes L, McIntyre S, Lindenmayer DB, Parmesan C, Possingham HP, and Thomas 464 CD. 2008. Assisted colonization and rapid climate change. Science 321:345-346.

465 Hopley D. 2006. Coral reef growth on the shelf margin of the Great Barrier Reef with special reference to 466 the Pompey Complex. Journal of Coastal Research 22:150-174.

467 Hubisz MJ, Falush D, Stephens M, and Pritchard JK. 2009. Inferring weak population structure with the 468 assistance of sample group information. Molecular Ecology Resources 9:1322-1332. 
469 Hughes TP, Baird AH, Dinsdale EA, Moltschaniwskyj NA, Pratchett MS, Tanner JE, and Willis BL.

470 2000. Supply-side ecology works both ways: The link between bethic adults, fecundity, and larval $471 \quad$ recruits. Ecology 81:2241-2249.

472 Jakobsson M, and Rosenberg NA. 2007. CLUMPP: a cluster matching and permutation program for 473 dealing with label switching and multimodality in analysis of population structure. Bioinformatics $474 \quad 23: 1801-1806$.

475 Jensen JL, Bohonak AJ, and Kelley ST. 2005. Isolation by distance, web service. BMC Genetics 6:13. 476 Jones A, and Berkelmans R. 2010. Potential costs of acclimatization to a warmer climate: Growth of a 477 reef coral with heat tolerant vs. sensitive symbiont rypes. PLoS ONE 5:e10437.

478 Jones AM, and Berkelmans R. 2011. Tradeoffs to thermal acclimation: energetics and reproduction of a 479 reef coral with heat tolerant Symbiodinium type-D. Journal of Marine Biology

$480 \quad$ 2011:doi:10.1155/2011/185890.

481 Jones AM, and Berkelmans R. 2014. Flood Impacts in Keppel Bay, Southern Great Barrier Reef in the 482 Aftermath of Cyclonic Rainfall. PLoS ONE 9:e84739.

483 Jones AM, Berkelmans R, and Houston W. 2011. Species richness and community structure on a high 484 latitude reef: Implications for conservation and management. Diversity 3:329-355.

485 Jones AM, Berkelmans R, van Oppen MJH, Mieog JC, and Sinclair W. 2008. A community change in the 486 algal endosymbionts of a scleractinian coral following a natural bleaching event: field evidence of 487 acclimatization. Proceedings of the Royal Society B-Biological Sciences 275:1359-1365.

488 Jost L. 2008. G(ST) and its relatives do not measure differentiation. Molecular ecology 17:4015-4026.

489 Luick JL, Mason L, Hardy T, and Furnas MJ. 2007. Circulation in the Great Barrier Reef Lagoon using $490 \quad$ numerical tracers and in situ data. Continental Shelf Research 27:757-778.

491 Luikart G, and Cornuet JM. 1998. Empirical evaluation of a test for identifying recently bottlenecked 492 populations from allele frequency data. Conservation Biology 12:228-237. 
493 Lukoschek V, Cross P, Torda G, Zimmerman R, and Willis BL. 2013. The importance of coral larval 494 recruitment for the recovery of reefs impacted by cyclone Yasi in the Central Great Barrier Reef. 495 PLOS ONE 8: e65363.

496 Michalek-Wagner K, and Willis BL. 2001. Impacts of bleaching on the soft coral Lobophytum

497 compactum. I. Fecundity, fertilization and offspring viability. Coral Reefs 19:231-239.

498 Narum SR. 2006. Beyond Bonferroni: Less conservative analyses for conservation genetics. Conservation $499 \quad$ Genetics 7:783-787.

500 Nishikawa A, Katoh M, and Sakai K. 2003. Larval settlement rates and gene flow of broadcast-spawning 501 (Acropora tenuis) and planula-brooding (Stylophora pistillata) corals. Marine Ecology Progress 502 Series 256:87-97.

503 Omori M. 2010. Degradation and restoration of coral reefs: Experience in Okinawa, Japan. Marine 504 Biology Research 7:3-12.

505 Paetkau D, Slade R, Burden M and Estoup A. 2004. Genetic assignment methods for the direct, real-time 506 estimation of migration rate: a simulation-based exploration of accuracy and power. Molecular $507 \quad$ Ecology 13:55-65.

508 Peakall R, and Smouse PE. 2006. GENALEX 6: genetic analysis in Excel. Population genetic software 509 for teaching and research. Molecular Ecology Notes 6:288-295.

510 Pickard GL. 1977. A review of the physical oceanography of the Great Barrier Reef and Western Coral 511 Sea Australia 1. The Great Barrier Reef. Australian Institute of Marine Science Monograph Series $512 \quad 2: 1-60$

513 Piry S, Alapetite A, Cornuet JM, Paetkau D, Baudouin L, and Estoup A. 2004. GENECLASS2: A

514 software for genetic assignment and first-generation migrant detection. Journal of Heredity 95: 536$515 \quad 539$.

516 Prada C, and Hellberg ME. 2014. Strong natural selection on juveniles maintains a narrow adult hybrid 517 zone in a marine broadcast spawner. American Naturalist 184:702-713. 
518 Pritchard JK, Stephens M, and Donnelly P. 2000. Inference of population structure using multilocus 519 genotype data. Genetics 155:945-959.

520 Rannala B, and Mountain JL. 1997. Detecting immigration by using multilocus genotypes._Proceedings 521 of the National Academy of Science, USA 94:9197-9201.

522 Raymond M, and Rousset F. 1995 GENEPOP (version 1.2): population genetics software for exact tests 523 and ecumenicism Journal of Heredity 86:248-249.

524 Riegl B, and Piller WE. 2001. "Cryptic" tissues inside Acropora frame works (Indonesia): a mechanism 525 to enhance tissue survival in hard times while also increasing framework density. Coral Reefs 20:67$526 \quad 68$.

527 Rosenberg NA. 2004. DISTRUCT: a program for the graphical display of population structure. Molecular $528 \quad$ Ecology Notes 4:137-138.

529 Smith LD, and Hughes TP. 1999. An experimental assessment of survival, re-attachment and fecundity of coral fragments. Journal of Experimental Marine Biology and Ecology 235:147-164.

531 Underwood JN, Smith LD, Van Oppen MJH, and Gilmour JP. 2007. Multiple scales of genetic connectivity in a brooding coral on isolated reefs following catastrophic bleaching. Molecular Ecology 16:771-784.

van Oppen MJH, Lutz A, De'ath G, Peplow L, and Kininmonth S. 2008. Genetic traces of recent longdistance dispersal in a predominantly self-recruiting coral. PLoS ONE 3:e3401. factors shape the population genetic structure of the broadcast spawning coral, Acropora millepora, on the Great Barrier Reef. Molecular Ecology 20:4899-4914.

van Oppen MJH, Puill-Stephan E, Lundgren P, De'ath G, and Bay LK. 2014. First generation fitness consequences of interpopulational hybridisation in a Great Barrier Reef coral and its implications for assisted migration management. Coral Reefs 33:607-611.

Van Woesik R, DeVantier LM, and Glazebrook JS. 1995. Effects of cyclone 'Joy' on nearshore coral communities of the Great Barrier Reef. Marine Ecology-Progress Series 128:261-270. 
544 Waits LP, Luikart G, and Taberlet P. 2001. Estimating the probability of identity among genotypes in 545 natural populations: cautions and guidelines. Molecular Ecology 10:249-256.

546 Wang S, Zhang LL, and Matz M. 2009. Microsatellite characterization and marker development from 547 public EST and WGS databases in the reef-building coral Acropora millepora (Cnidaria, Anthozoa, 548 Scleractinia). Journal of Heredity 100:329-337.

549 Whitaker K. 2004. Non-random mating and population genetic subdivision of two broadcasting corals at $550 \quad$ Ningaloo Reef, Western Australia. Marine Biology 144:593-603.

551 Wilson K, Li Y, Whan V, Lehnert S, Byrne K, Moore S, Pongsomboon S, Tassanakajon A, Rosenberg G, 552 E. B, Fayazi Z, Swan J, Kenway M, and Benzie J. 2002. Genetic mapping of the black tiger shrimp 553 Penaeus monodon with amplified fragment length polymorphism. Aquaculture 204:297-309.

554

555 
556 Figure 1. Map of sampling locations of Acropora millepora (black circles), in this (bottom) and the van

557 Oppen et al (2011) (top) studies. Colour plots on the right-hand side of the maps represent the TESS

558 results using the admixture model and $\mathrm{K}=5$. Each bar represents an individual coral colony and the five 559 colours represent the five genetic clusters.

560

561 Figure 2. Image showing a typical shallow water reef in the Keppel Island archipelago dominated by 562 Acropora millepora. Photo credit: Alison Jones. 


\section{Table $\mathbf{1}$ (on next page)}

Table 1

Pairwise $D_{\text {est }}$ values, below diagonal, $\mathrm{p}$-values above diagonal.

Most values are statistically significant; non-significant values have shaded background, and $p$-values larger than adjusted $\alpha$ are printed in bold face (adjusted $\alpha=0.012$ ). 
1 Table 1: Pairwise $D_{\text {est }}$ values, below diagonal, p-values above diagonal. Most values are statistically

2 significant; non-significant values have shaded background, and p-values larger than adjusted $\alpha$ are

3 printed in bold face (adjusted $\alpha=0.012$ ).

4

\begin{tabular}{|c|c|c|c|c|c|c|c|c|c|}
\hline & $\begin{array}{l}\text { Barren } \\
\text { Island }\end{array}$ & $\begin{array}{l}\text { Halftide } \\
\text { Rocks }\end{array}$ & $\begin{array}{l}\text { Halfway } \\
\text { Island }\end{array}$ & $\begin{array}{l}\text { Humpy } \\
\text { Island }\end{array}$ & $\begin{array}{l}\text { Man\&Wife } \\
\text { Rocks }\end{array}$ & $\begin{array}{l}\text { Miall } \\
\text { Island }\end{array}$ & $\begin{array}{l}\text { Nth } \\
\text { Keppel } \\
\text { Island }\end{array}$ & $\begin{array}{l}\text { Outer } \\
\text { Rocks }\end{array}$ & $\begin{array}{l}\text { Passage } \\
\text { Rocks }\end{array}$ \\
\hline Barren & & 0.001 & 0.001 & 0.001 & 0.001 & 0.001 & 0.001 & 0.001 & 0.001 \\
\hline Halftide & 0.253 & & 0.027 & 0.001 & 0.001 & 0.001 & 0.001 & 0.001 & 0.001 \\
\hline Halfway & 0.212 & 0.012 & & 0.024 & 0.001 & 0.017 & 0.392 & 0.088 & 0.001 \\
\hline Humpy & 0.192 & 0.038 & 0.015 & & 0.001 & 0.080 & 0.020 & 0.016 & 0.003 \\
\hline Man\&Wife & 0.176 & 0.077 & 0.054 & 0.059 & & 0.001 & 0.002 & 0.009 & 0.001 \\
\hline Miall & 0.239 & 0.042 & 0.017 & 0.010 & 0.084 & & 0.070 & 0.037 & 0.001 \\
\hline Nth & & & & & & & & & \\
\hline Keppel & 0.221 & 0.030 & 0.001 & 0.018 & 0.064 & 0.011 & & 0.097 & 0.001 \\
\hline Outer & 0.175 & 0.040 & 0.009 & 0.020 & 0.041 & 0.014 & 0.010 & & 0.001 \\
\hline Passage & 0.242 & 0.119 & 0.091 & 0.032 & 0.125 & 0.100 & 0.089 & 0.110 & \\
\hline
\end{tabular}

5 
Figure $\mathbf{1}$ (on next page)

Figure 1

Map of sampling locations of Acropora millepora (black circles), in this (bottom) and the van Oppen et al (2011) (top) studies. Colour plots on the right-hand side of the maps represent the TESS results using the admixture model and $K=5$. Each bar represents an individual coral colony and the five colours represent the five genetic clusters. 


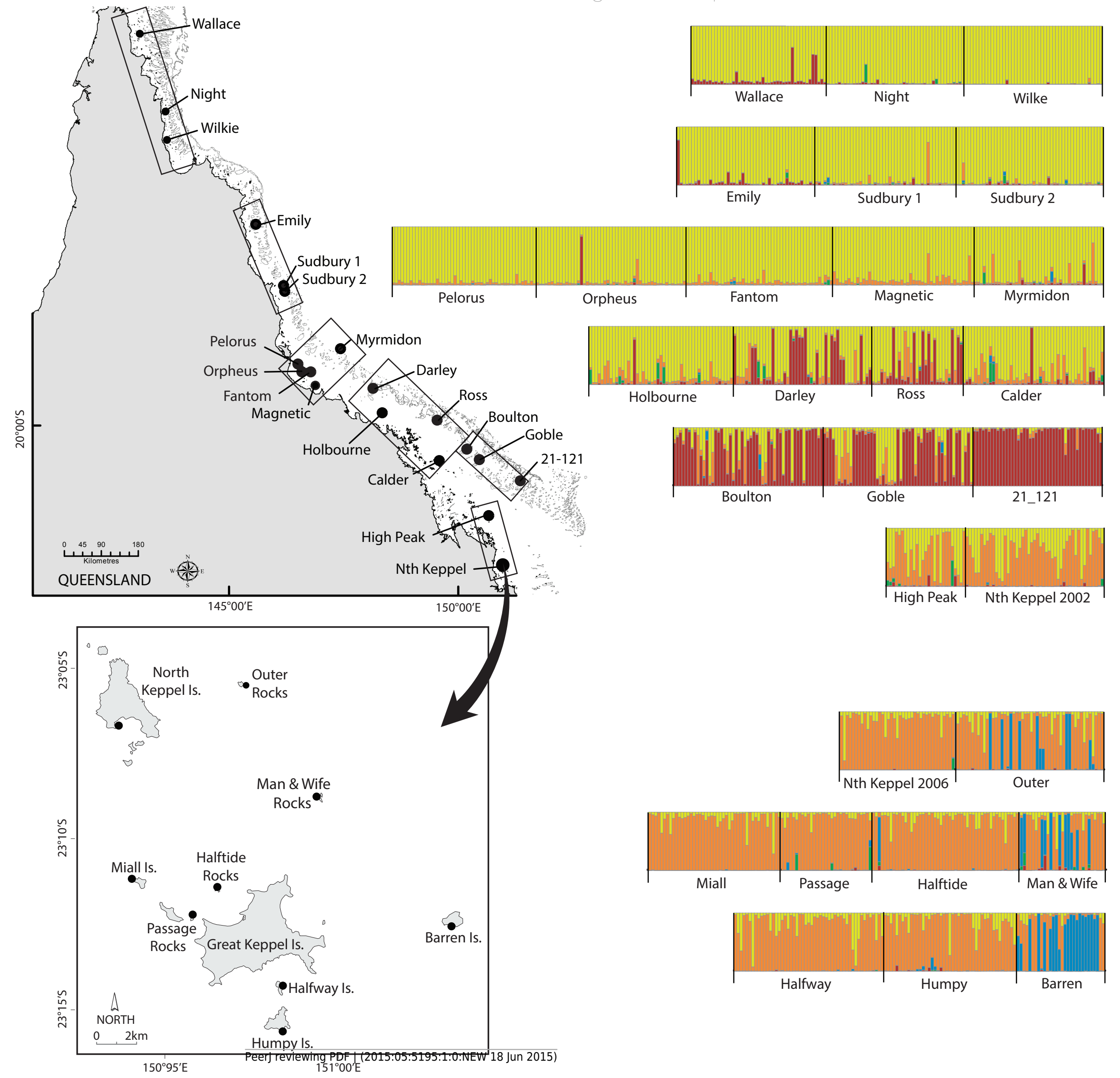




\section{2}

Figure 2

Image showing a typical shallow water reef in the Keppel Island archipelago, dominated by Acropora millepora. Photo credit: Alison Jones.

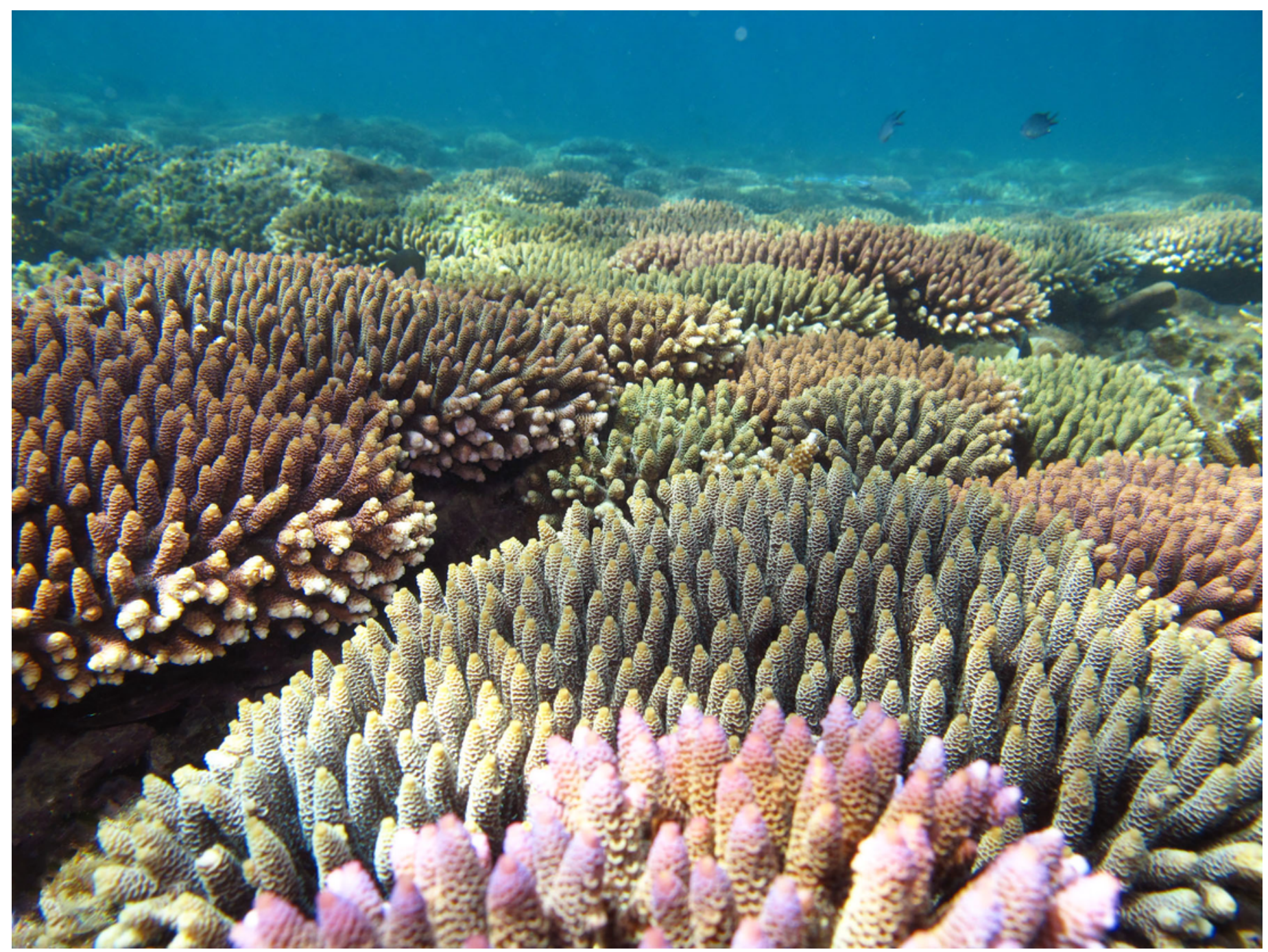

